\title{
Head Nurses Knowledge about Conflict Management Strategies, Mediation, and Negotiation Styles
}

\author{
Hanaa Mohammed Ahmed, Hoda Diab Fahmy Ibrahim, Hala Ramzy Yousef \& Sahar Mohamed Morsy \\ Assistant lecturer of Nursing Administration, Faculty of Nursing, Assuit University, Egypt. \\ Professors of Community Health Nursing, Faculty of Nursing, Assuit University, Egypt. \\ Assist. Professors of Nursing Administration, Faculty of Nursing, Assuit University, Egypt.
}

\begin{abstract}
Background: Conflict is the consequence of real or perceived differences in mutually exclusive goals, values, ideas, attitudes, beliefs, feelings, and actions. Aims: Assess of head nurses' knowledge about conflict management strategies, mediation and negotiation styles of conflict resolution. Study subject: It was included all head nurses working at the Main Assiut University Hospital ( $\mathrm{n}=113)$. Study tools: included four tools to assess the studied head nurses' knowledge, such as personal characteristics tool, conflict management questionnaire tool, mediation style tool, and negotiation style tool. Results: the highest percentage of studied head nurses had low knowledge of all items of conflict management content and mediation \& negotiation strategies. Conclusion: The majority of studied head nurses had low knowledge with regard to conflict management content, conflict resolution strategies and mediation \& negotiation styles. Recommendation: Designing and implementing an educational program about mediation and negotiation styles of conflict resolution and providing courses about conflict management should be provided periodically, to help head nurses acquainted with the new knowledge.
\end{abstract}

\section{Keywords: Conflict Management, Head Nurses, Mediation \& Negotiation Styles.}

\section{Introduction}

Conflict is a phenomenon infinitely complex dimension, in tangles, represents its existence a reality the human fixed features (Hess, 2015). Conflict resolution styles are avoiding, competing, collaborating, compromising, accommodating, mediation and negotiation (Coleman, 2015). Mediation and negotiation are procedures for resolving opposing preferences between the parties; negotiation involves discussion between the parties with the goal of reaching an agreement (Daiski, 2014). While, mediation is a variation on negotiation in which one or more outsiders "third parties" assist the parties in their discussion (Root, 2014). By understanding the dynamics of mediation and negotiation in areas such as leadership, power, and conflict management, healthcare professionals will improve the quality of their professional practice, relationships and their working environment (Berman, 2014). Mediation is a voluntary, nonbinding, private dispute resolution process, through a neutral person helps the parties to reach the negotiated settlement (Schlairet, 2009). It includes the following styles: facilitative, evaluative and transformative mediation, Facilitative mediation, in which the mediator structure a process to assist the parties in reaching a mutually agreeable resolution (Tomey, 2009).

Negotiation is a process of digging into an issue to identify underlying individual concerns and find alternatives that meet most or all sets of concerns
(Collins, 2012). Negotiation in its most creative form is similar to collaboration and in its most poorly managed form may resemble a competing approach. It frequently resembles compromise when it is used as a conflict resolution strategy (Novak, 2012).

Mediation and negotiation are procedures for resolving opposing preferences between the parties (Fiumano, 2012). Negotiation involves discussion between the parties with the goal of reaching an agreement. There is no limit to the number of parties ("disputants") who can take part in negotiation, but two-party negotiations are the kind most often studied (Nastakis, 2013). Mediation is a variation on negotiation in which one or more outsiders ("third parties") assist the parties in their discussion.

\section{Significance of the study}

Healthcare organizations must find ways for managing conflict and developing effective working relationships to create healthy work environments (Collins, 2012). So, should be used of more effective negotiation and mediation strategies which have been identified as an essential component of the nurse manager role (Anthony, et al., 2014). It was noticed that there were no studies done in Upper Egypt about mediation and negotiation as strategies for conflict management, so the investigator desirous to study the phenomenon among head nurses through assesses 
their knowledge about conflict management strategies \& mediation and negotiation styles of conflict resolution at the Main Assuit University Hospital.

\section{Aim of the study}

The present study aimed to: assess knowledge of head nurses about conflict management strategies, mediation and negotiation styles of conflict resolutions at the Main Assiut University Hospital.

\section{Subject\& methods}

A-Study design: Descriptive research design was used.

B-Setting: The present study conducted at the Main Assiut University Hospital.

C-Study subject: It was included all head nurses $(n=113)$, working in general and special medical departments, general and special surgical departments, ICU, Emergency units at Main Assiut University Hospital.

D-Study tools: included four tools, as the following:

- Personal characteristics questionnaire: It was developed by the investigator to collect data about head nurses as age, gender, level of education, marital status, and years of experience.

- Conflict management questionnaire: It was developed by the investigator to assess head nurses' knowledge about conflict management and consisted of (46 items) classified into six categories, namely: The definition and types of conflict include (9 items), causes of conflict includes (17 items), the positive effect of conflict includes (6 items), it was developed by the investigator to assess head nurses' knowledge about conflict management. The negative effect of conflict includes (6 items) based on related literature of (Gillies, 2012, Yoder, 2010 \& Ahmed, 2008) and conflict management strategies include (3 items), conflict resolution styles (5 items). Head nurses' responses ranging (1) mark for yes answer and (zero) mark for No answer.

- Mediation style of conflict resolution questionnaire: It was developed by the investigator to assess head nurses' knowledge about mediation style of conflict resolution and consisted of 37 items. Head nurses responses based on 3 points Likert scale ranging (3) marks for an always answer, (2) marks for a sometimes answer and (1) mark for a never answer.

- Negotiation style of conflict resolution questionnaire: It was developed by the investigator to assess head nurses' knowledge about negotiation style of conflict resolution and consisted of 31 items. Head nurses responses based on 3 points Likert scale ranging (3) marks for an always answer, (2) marks for a sometimes answer and (1) mark for a never answer.

\section{Methods}

I- Operational design

1-Preparatory phase

After reviewing the available literature concerning the topic of the study, the investigator developed and translated of assessment tools from English to Arabic was done. It took about Four months from September to December 2013 and the validity of the assessment tool reviewed by the experts of the nursing administration (Jury from three expertise in the specialty) to check the relevance, coverage, and clarity of the questions. Accordingly, modifications were done and the final form was developed. This phase took about three months from February to March; 2014.this design explains the steps of actual implementation of the study.

\section{2-Pilot study}

A pilot study was carried out to assess tools, clarity, and applicability. Moreover, to identify problems that may be encountered during the actual data collection. It applied on eleven Head nurses (10\%) from the main hospital included in the study sample of the selected from main Assiut university hospitals. Reliability analysis of the results and the researcher done the modification of items after justifying the comment of Jury and before the pilot study to provide the reliability of the study tool. It was equal $(\alpha=$ $0.88 \%$ ). It took about two months from April to May 2014.

\section{II-Administrative design}

Official permission obtained to collect data from the directors of the Main Assiut University Hospital, official permission obtained to collect necessary data from the general director of Nursing, director of the Nursing Administration department at the Main Assiut University Hospital. Ethical consideration obtained with oral consent taken from the studied head nurses before getting the data in the present study.

\section{III- Statistical design}

Collected data were verified prior to computerized data entry and analysis by using statistical software packages for social sciences (SPSS) v.g 20.program. Data were presented using descriptive statistics in the form of percentages also mean and standard deviations were calculated. 


\section{Results}

Table (1) Personal characteristics of the studied head nurses at Main Assiut University Hospital ( $n=113$ ).

\begin{tabular}{|c|c|c|}
\hline Items & No. & $\%$ \\
\hline \multicolumn{3}{|l|}{ 1-Age: (years) } \\
\hline$<35 \downarrow$ & 16 & 14.2 \\
\hline $35-<40 \downarrow$ & 77 & 68.1 \\
\hline $40-<45 \downarrow$ & 10 & 8.8 \\
\hline $45-<48 \uparrow$ & 10 & 8.8 \\
\hline $\begin{array}{l}\text { Range: } \\
22-48 \uparrow \text { years. }\end{array}$ & \multicolumn{2}{|c|}{$\begin{array}{c}\text { Mean } \pm \text { SD } \\
31.9 \pm 6.9\end{array}$} \\
\hline \multicolumn{3}{|l|}{ 2-Gender } \\
\hline Male. & 9 & 8.0 \\
\hline Female. & 104 & 92.0 \\
\hline \multicolumn{3}{|l|}{ 3-Level of education } \\
\hline \begin{tabular}{|l|} 
Diploma of secondary technical school. \\
\end{tabular} & 4 & 3.5 \\
\hline Nursing technical institute. & 7 & 6.2 \\
\hline Bachelor of nursing science. & 92 & 81.4 \\
\hline Master of nursing degree. & 10 & 8.8 \\
\hline \multicolumn{3}{|l|}{ 4-Marital status } \\
\hline $\begin{array}{c}\text { Single. } \\
\end{array}$ & 37 & 32.7 \\
\hline Married. & 73 & 64.6 \\
\hline Divorced. & 2 & 1.8 \\
\hline Widow. & 1 & 0.9 \\
\hline \multicolumn{3}{|l|}{ 5-Years of experience } \\
\hline $\begin{array}{c}<5 \text { years } \\
\end{array}$ & 40 & 35.4 \\
\hline 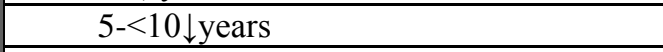 & 29 & 25.7 \\
\hline $10-\geq 15 \uparrow$ years. & 44 & 38.9 \\
\hline
\end{tabular}

\begin{tabular}{|c|c|c|c|c|c|c|c|c|c|}
\hline \multicolumn{1}{|c|}{} & \\
\hline
\end{tabular}

Fig. (1) Distribution of head nurses' knowledge regarding the definition and types of conflict. 


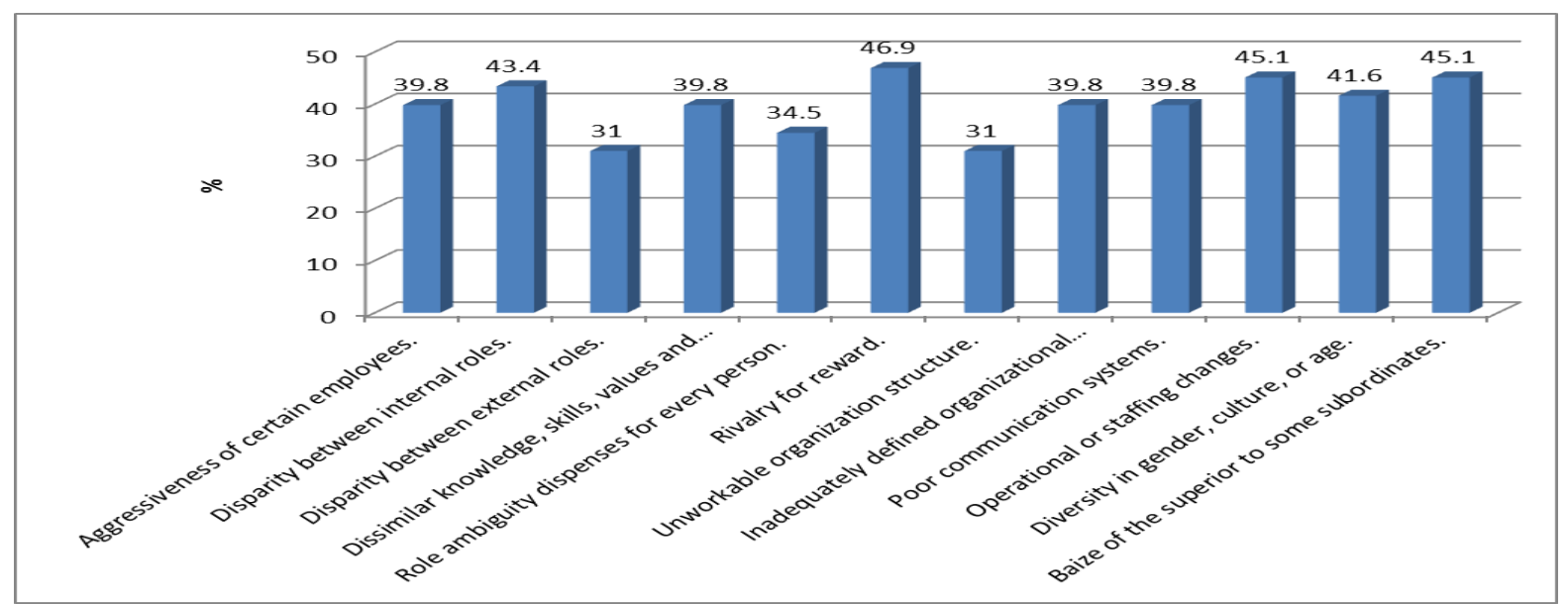

Fig. (2): Distribution of head nurses knowledge regarding the causes of conflict.

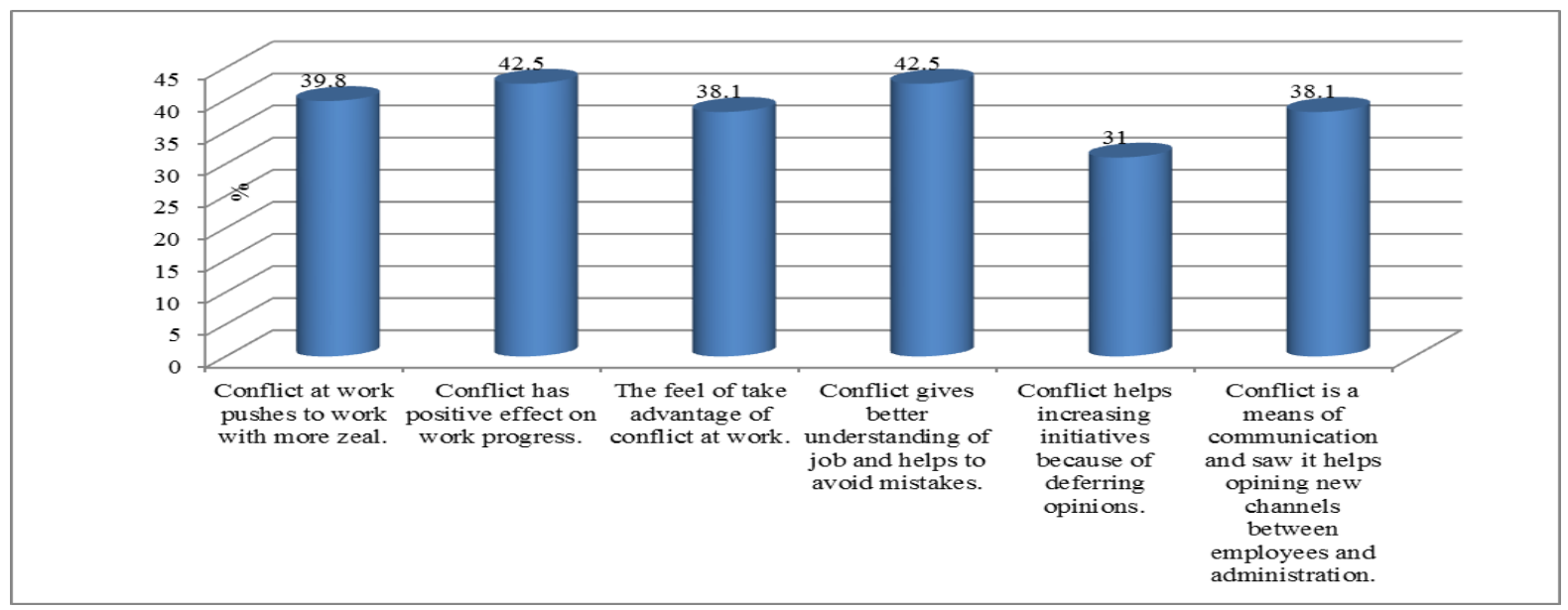

Fig.(3):Distribution of head nurses' knowledge regarding the positive effect of conflict.

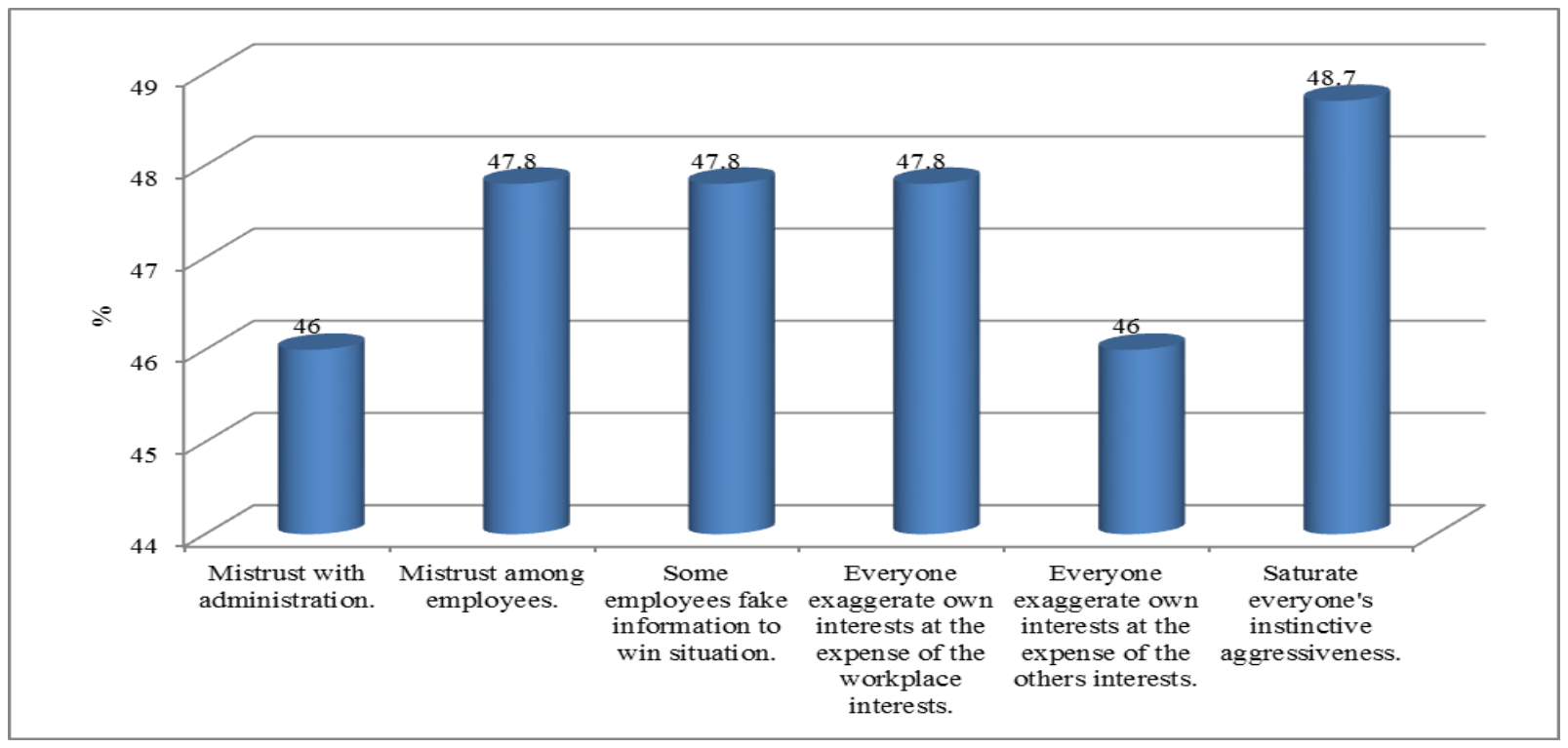

Fig.(4): Distribution of head nurses' knowledge regarding the negative effect of conflict. 


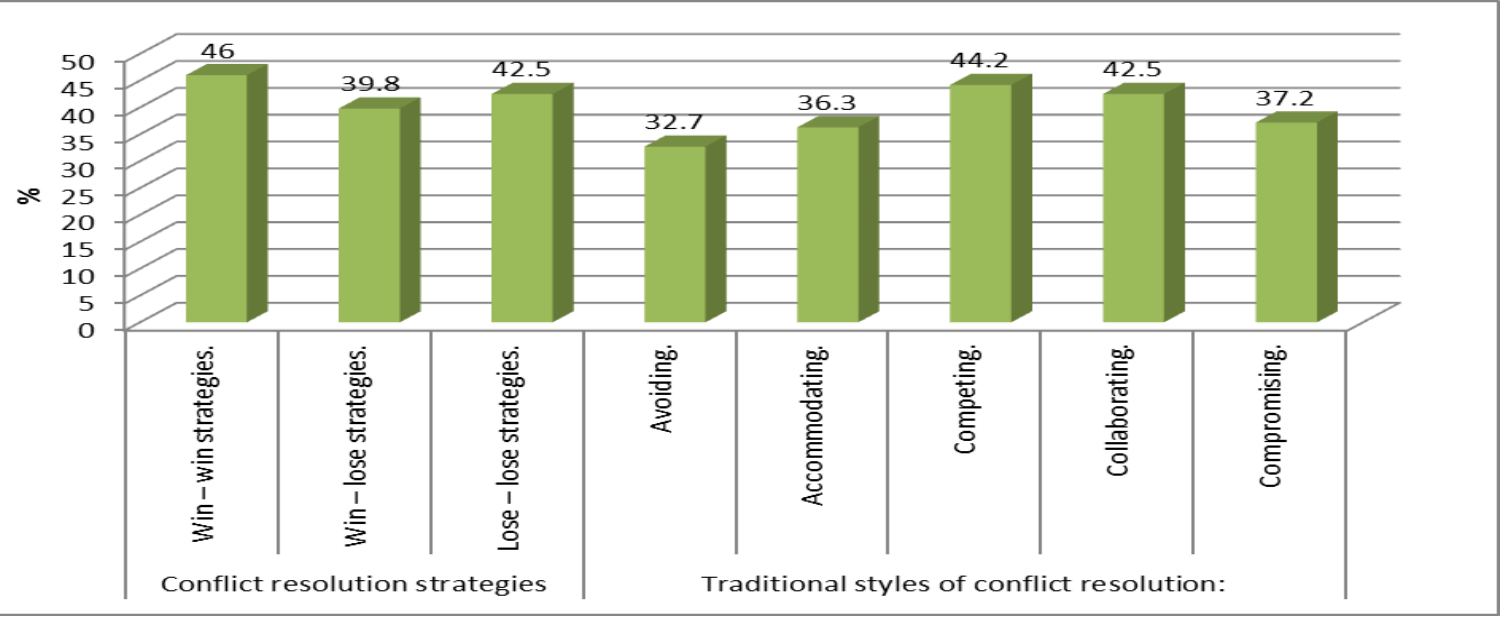

Fig. (5): Distribution of head nurses' knowledge regarding the conflict resolution strategies and traditional styles.

Table(2):Distribution of head nurses' knowledge regarding the mediation and negotiation as alternative strategies of conflict resolution.

\begin{tabular}{|l|c|c|c|c|c|c|}
\hline \multirow{2}{*}{ Alternative strategies } & \multicolumn{2}{|c|}{ Never } & \multicolumn{2}{c|}{ Sometimes } & \multicolumn{2}{c|}{ Always } \\
\cline { 2 - 7 } & No. & \% & No. & \% & No. & \% \\
\hline 1. Mediation strategy. & 50 & 44.2 & 33 & 29.2 & 30 & 26.5 \\
\hline 2. Negotiation strategy. & 48 & 42.5 & 36 & 31.9 & 29 & 25.7 \\
\hline
\end{tabular}

Table (3): Mean scores of head nurses' knowledge regarding conflict management content.

\begin{tabular}{|c|c|c|c|c|c|c|c|c|}
\hline \multirow{2}{*}{ Variables } & \multirow{2}{*}{$\begin{array}{l}\text { Total } \\
\text { score }\end{array}$} & \multirow{2}{*}{ Mean \pm SD } & \multicolumn{2}{|c|}{ Low } & \multicolumn{2}{|c|}{ Moderate } & \multicolumn{2}{|c|}{ High } \\
\hline & & & No. & $\%$ & No. & $\%$ & No. & $\%$ \\
\hline 1. Definition \& types of conflict. & 9 & $5.1+3.7$ & 54 & 47.8 & 10 & 8.8 & 49 & 43.4 \\
\hline 2. Causes of conflict. & 17 & $8.5+6.4$ & 59 & 52.2 & 13 & 11.5 & 41 & 36.3 \\
\hline 3. Positive effects of conflict. & 6 & $2.6+2.3$ & 63 & 55.8 & 15 & 13.3 & 35 & 31.0 \\
\hline 4. Negative effects of conflict & 6 & $3.1+2.4$ & 54 & 47.8 & 17 & 15.0 & 42 & 37.2 \\
\hline 5. Conflict management strategies & 3 & $1.6+1.2$ & 54 & 47.8 & 17 & 15.0 & 42 & 37.2 \\
\hline 6. Conflict resolution styles. & 5 & $2.3+1.8$ & 60 & 53.1 & 20 & 17.7 & 33 & 29.2 \\
\hline 7. Mediation style. & 111 & $65.1+22.5$ & 50 & 44.2 & 33 & 29.2 & 30 & 26.5 \\
\hline 8. Negotiation style. & 93 & $54.7+19$ & 48 & 42.5 & 36 & 31.9 & 29 & 25.7 \\
\hline
\end{tabular}

Table (1): showed that, personal characteristics of the studied head nurses showed in The highest percentage of them were female, have a bachelor degree in nursing science, their age from 35 to less than 40 years old, married, and having experience from 10 to more than 15 years $(92.0 \%, 81.4 \%$, $68.1 \%, 64.6 \%$ and $39.0 \%$ ) respectively.

Head nurses' knowledge regarding the definition and types of conflict. The most of the studied head nurses had knowledge regarding the definition and vertical type of conflict $(27.4 \% \& 45.1 \%)$ respectively. Revealed in, Fig (1)

Head nurses' knowledge regarding the causes of conflict showed in Fig. (2). The highest percentage of the studied head nurses had knowledge regarding the causes of conflict in terms at the lack of resources and rivalry for reward $(46.9 \% \& 46.9 \%)$ respectively. Fig. (3): Illustrated that, Head nurses' knowledge regarding the positive effect of conflict. The majority of the studied head nurses had knowledge regarding the positive effect of conflict in terms of conflict affects work progress and gives a better understanding of the job and helps to avoid mistakes $(42.5 \%$ \& $42.5 \%)$ respectively.

Head nurses' knowledge regarding the negative effect of conflict described in Fig (4). The most of the studied head nurses had knowledge as regards to saturate everyone's instinctive aggressiveness $(48.7 \%)$.

Head nurses' knowledge regarding the conflict 
resolution strategies and styles of conflict resolution illustrated in Fig (5). Below of the half of them had knowledge regards to the win- win strategies (46\%) and competing style of conflict resolution (44.2\%).

Table (2): depicted that, Head nurses' knowledge regarding the mediation and negotiation styles of conflict resolution. The majority of the studied head nurses had low knowledge as regards to the mediation and negotiation strategies of conflict resolution $(44.2 \% \& 42.5 \%)$ respectively.

Table (3): Illustrated that, Mean scores of head nurses' knowledge regarding conflict management content. The majority of the studied head nurses had low knowledge as regards to the conflict management content, conflict resolution strategies and mediation $\&$ negotiation strategies of conflict resolution.

\section{Discussion}

The highest percentage of the present studied head nurses had knowledge regarding the vertical conflict type; this might be the common type of conflict occurs in the hospital between the nurse manager and the subordinate. This finding consistent with Almost, (2010) who reported that the highest percent of health care professionals was conflicted because it occurs at work with superior one to five times per week. While it was disagreed with Al Deep, (2005) who had shown that the highest percentage of the participant's reported that interpersonal and intergroup type of conflict occurred due to a shortage of resources.

The high percentage of the studied head nurses had a knowledge regarding the causes of conflict, especially lack of resources and rivalry for reward, due to the main causes of conflict in the hospital related to the inequitable distribution of resources among patient care units and absence system of distributing rewards. This was observed in the present study. This finding consistent with Abdel Aziz, (2009) found that shortage of resources was the most important cause of conflict in their study. The present study finding inconsistent with Skjorshammer, (2011) who reported that the most common causes of conflict within a healthcare facility are personal differences, lack of clear job descriptions and responsibilities, role incompatibility and organizational issues, and organizational problems and communication gaps were the main issues creating conflict.

From this study finding the highest percentage of the studied head nurses had a knowledge regarding the positive effect of conflict on work progress and gives a better understanding of the job and helps to avoid mistakes. This might be the subordinates afraid of the director punishment, so avoid the mistakes occur. With this respect Sullivan \& Decker, (2009) who reported that nurses needed the conflict to change their attitudes and prerequisite to positive changes and progress of the work.

According to the present study finding, the highest percentage of the studied head nurses had knowledge about saturating everyone's instinctive aggressiveness as a negative effect of conflict. This might be used by competing for style by the manager it has reflected on the subordinates to consider this item as a common negative effect occurs in the work setting. This is congruent with Harmer, (2006) who explored that, the negative consequence of conflict lead to avoiding the health professional nurse to communicate with the aggressive nurse manager to prevent conflict occurred.

The highest percentage of this studied head nurses had knowledge about the strategies of conflict management and traditional styles of conflict resolution in terms win- win strategy and competing for the style of conflict resolution. In agreement with the study of Jenkins, (2015) who suggested that competing or forcing the issue in a conflict involves working for a particular desired solution exclusively. People who routinely address conflict in a competitive manner emphasize personal goals and desires, failing to consider the needs and opinions of others. These individuals have a strong need to come out of any conflict as the winner. Youssef et al., (2008) reported that the most of the study subject using the accommodating style of conflict resolution in their working settings. And Abdel Aziz, (2009) reported that the highest percent of the studied head nurses were using the avoiding style followed by a competing style to resolve the conflict. On the other hand, the present study disagrees with Yoder, (2010) showed that the majority of respondents agreed that avoiding and collaborating styles were the preferable styles of conflict resolution disagree with the present study.

Also, Kelly, (2010) reported that the problem-solving style provides manage change and plays a vital role in one's success through collaborative efforts and had a strong impact on the organization's bottom line and overall success. Moreover, El Dahshan \& Keshk, (2014) found that the most of the studied subjects used to avoid style, but the least used style was competing, however for improvement of the organizational problem by resolving the conflict. And, Ibrahim, (2015) who revealed that the majority of the study subject reported the common style clear at El Mansoura University Hospital was compromise style also disagree with the present study.

The current study finding revealed that the majority of the studied head nurses had low knowledge regarding the mediation and negotiation style of conflict resolutions; because some health care 
professionals in this hospital had a lack of information and in attendance of in-service educational workshops or programs about conflict resolution styles. This finding in contrast with Pavlakisl, et al., (2011) suggested that, a wide range of methods and procedures for addressing conflict exist, including negotiation, mediation, and creative peacebuilding. In the contrasted to Raines, (2015) who showed that all health practitioners had a high knowledge about alternative conflict resolution styles because dedicated to supporting and improving the field of alternative styles resolution by providing continuous workshops.

\section{Conclusion}

In the light of the study results, the majority of the studied head nurses had poor knowledge with regard to conflict management content, conflict resolution strategies and mediation \& negotiation styles of conflict resolution.

\section{Recommendations}

- Designing and implementing of an educational program about mediation and negotiation styles of conflict resolution.

- Provide courses about conflict management periodically, to help head nurses acquainted with the new knowledge.

\section{References}

1. Ahmed, A., (2008): the organizational climate in conflict management among nursing personnel working at Assiut University Hospitals, P.p $1-8$ MSc. Thesis, Faculty of nursing, Assiut University hospitals.

2. Abdel - Aziz, L., (2009): Implementation of conflict resolution strategies and its effect on stress level among nursing personnel at Benha university hospital, P.p 1-4.Ph.D. Thesis, Faculty of nursing, Benha University Hospital Retrieved from http://www.eulc.edu.eg/eulc_v5/Libraries/Thesis

3. Abo Gad, R., \& El-Demerdash, S., (2014): An Educational Program about Nursing Managers` Transformational Leadership, Conflict management Styles and Decision Making Effectiveness IOSR Journal of Nursing and Health Science 3, (3) PP 42-56. Retrieved from: www.iosrjournals.org.

4. Al Deep, N., (2005): Training Program on Intractable Conflict (OTPIC).Just as conflict scholars often distinguish between short-term conflicts. Retrieved from:

5. www.colorado.edu/conflict/peace/settlement.htm
6. Almost, J., (2010): intra-group conflict among nurses, and subsequently conflict management style, job stress, Doran DM, journal, 18(8): P.p. 81-92.

7. Anthony, D., Norrie, P., \& Al Hamdan, Z., (2014): Conflict management styles used by. Conflict can be interpersonal, intra-personal; intragroup used the Rahim Organization Conflict Inventory (ROCI II). Retrieved from: www.academia.edu.

8. Berman, L., (2014): 13 Tools for Resolving Conflict in the Workplace, with Customers and in Life by Brilliant Results Magazine, by the American Arbitration Association Inc, available at lee jay@mediationtools.com.

9. Coleman, P., (2015): Power and conflict. In: Deutsch M, Coleman P, Eds. The Handbook of Conflict Resolution: Theory and Practice. San Francisco: Jossey-Bass. Retrieved from: http:// www, books Google. com.eg.

10. Collins, W., (2012): Manage Conflict and Resolve Problems by Negotiating, by Colorado mediators \& arbitration usadr. Available at: http:// www, books Google. com.eg.

11. Daiski, I., (2014): Changing nurses' disempowering relationship patterns. Journal of Advanced Nursing, 48 (1), P.p, 43-50.

12. Dutta, P., (2013): What is The Definition of Staff Development? By Demand Media, Available at: http:// www, books google. com.eg.

13. El Dahshan, M., \& Keshk, L., (2014): Managers' Conflict Management Styles and its Effect on Staff Nurses' Turnover Intention at Shebin El Kom Hospitals, Menoufiya Governorate, World Journal of Medical Sciences 11 (1): 132-143.

14. Fiumano, J., (2012): Navigate through conflict, not around it. Nursing Management Journal, 36(8), P.P., 1-14. Retrieved from: https://books.google.com.eg/books?isbn=080364 0560

15. Gillies, A., (2012): Nursing management, a system approach, 3rd Ed, Pp. 472- 487, by W.B Saunders Inc.

16. Harmer, B., (2006): Do not go gentle, intractable value differences in the hospital. www.linkedin.com/pub/janellegustafson/69/37www.taayuon.4youth.org.

17. Hess R., (2015): Shared governance relation on conflict management. Online Journal of Issues in Nursing. Retrieved from: http://nursingworld.org.

18. Ibrahim, A., (2015): Leadership style and conflict management strategies of head nurses at Mansoura University Hospital, Thesis M.Sc 
.Retrieved from: http:// www.eulc. Edu./eulc. vs/ Librabries / start aspx.

19. Jenkins, D., (2015): Resolution or Transformation of Conflict or Transformation of Conflict Coordinator(s), Bert, Retrieved from: (bjenkins@une.edu.au).

20. Kelly, J., (2010): An overcoming of conflict. Dimensions of critical care nursing journal, 25(1), P.p.22-28.

21. Nastakis, D., (2013): Negotiation skills for physicians. Am Journal Surg. 1(8), P.p185, available at www.Wikimedia Foundation.

22. Novak, K., (2012): Conflict Negotiation Guidelines Section 4, Policy Toolkit for Strengthening Health Sector Reform, P.p 4-29, available at www.Wikimedia Foundation.

23. Pavlakis, A., Kaitelidou, M., Theodorou, P. Galanis, P., Sourtzi O., \& Siskou, A., (2011): Conflict Management in Public Hospitals: The Cyprus Case Journal, 58(3): P.p. 242-248.

24. Raines, S., (2015): Conflict Management for Managers: Resolving Workplace, Client, and Policy Disputes "With her broad dispute resolution, teaching, and editing experience ، Retrieved from:www.amazon.com/ConflictManagement-Managers-Resolving.

25. Root, I., (2014): Cause Analysis and Negotiation/Conflict Management Skills for Auditors by the Institute of Internal Auditors Baltimore Chapter.

26. Retrieved from: http://www.eventbrite.com.

27. Schlairet, C., (2009): Bioethics mediation: The role and importance of nursing advocacy, Nursing Outlook Journal, 57, (4), P.p 185-193.

28. Skjorshammer, M., (2011): Conflict management in a hospital: designing processing structures and intervention methods. Journal of Management in Medicine, 15:P.p.156-166.

29. Sullivan, E., \& Decker, P., (2009): Effective Leadership and Management in Nursing. $7^{\text {th }}$ Ed, by Prentice London Inc. Available at: https://books.google.com.eg/books.

30. Tomey, M., (2009): Guide to nursing management and leadership $8^{\text {th }}$ edition, P.p 146159 by Elsevier inc.

31. Yoder, W., (2010): Care managers realize that conflict is a natural and inevitable process in organizations, and often it is also as the cutting edge of change. Retrieved from: https://books.google.com.eg/books.

32. Youssef, H., Aref, S., Abdellah, S., \& Mohammed, A., (2008): Nurse's styles in managing conflict at Assiut University Hospital, The new journal of medicine, 30(5), P.P.1-8. 